\title{
LA HERMENÉUTICA DE H.-G. GADAMER Y LOS IMPLÍCITOS HERMENÉUTICOS DE LA «SEGUNDA CONSIDERACIÓN INTEMPESTIVA» DE F. NIETZSCHE
}

\author{
Luis Enrique De Santiago Guervós \\ Universidad de Málaga
}

\begin{abstract}
RESUMEN. Un ensayo de aproximación de dos hermenéuticas tan ricas como la de Nietzsche y la de Gadamer es un camino fecundo que puede ayudarnos a comprender mejor la hermenéutica de este último, dentro de una tradición que pasa por Nietzsche, y al mismo tiempo a descubrir los implícitos hermenéuticos que oculta la filosofía de Nietzsche. A nadie se le escapa ya que los planteamientos sobre la interpretación de este sentaron las bases a desarrollos hermenéuticos posteriores, pero tal vez no se le haya hecho todavía justicia a Nietzsche respecto a su hermenéutica.
\end{abstract}

Cuando tratamos de confrontar dos hermenéuticas, en apariencia tan radicalmente opuestas, como la de Nietzsche y la de Gadamer, lo primero que puede pensarse es que se trata de reivindicar una en lugar de la otra. Este no es el caso. Lo verdaderamente interesante aquí es abrir una vía de investigación que tome conciencia de la cuestión hermenéutica con otras miras, a fin de poder enriquecer y ampliar el vasto campo de la teoría de la interpretación. En este sentido, tendríamos que pensar en incluir a Nietzsche en esa rica tradición hermenéutica, de la que se le ha excluido no pocas veces, posiblemente por su excesiva "radicalidad" al plantearse el problema fundamental de la interpretación. Pues bien, aquella manera tan radical y "extremista" de la filosofía de Nietzsche, que fascinaba tanto a Heidegger y que marcó de una manera determinante su camino del pensamiento, probablemente no era del gusto de Gadamer. El mismo solía decir con frecuencia que Nietzsche era ciertamente una provocación para todos, y que Heidegger supo darle una respuesta adecuada. Pero no parece, sin embar- 
go, que Gadamer atendiera a esa provocación, a pesar de que, según la apreciación de J. Grondin, «Nietzsche había puesto en marcha una universalización revolucionaria del enfoque perspectivístico e interpretativo, cuya consecuencia puede verse legítimamente en la hermenéutica del siglo $\mathrm{XX}^{\prime \prime}{ }^{1}$. No obstante, Gadamer reconoce con claridad que cuando la cultura occidental se vio sometida a una profunda crítica radical «la hermenéutica se convierte en una cuestión con un significado y alcance universales ${ }^{2}$, y un ejemplo de ese radicalismo lo encuentra precisamente en Nietzsche.

Por eso, siendo consecuentes con la propia hermenéutica de Gadamer, sería importante entablar un diálogo entre Nietzsche y él a fin de poder ser conscientes de sus coincidencias y de sus discrepancias. ¿Por qué hacer aquí una excepción? ¿Realmente Gadamer ha dejado oír la voz de Niezzsche -0 todas las modulaciones de su voz que se han producido a través de la historia más reciente de la filosofía? Si nos aproximamos de una manera benévola a las dos formas aparentemente distintas de enfocar sus planteamientos hermenéuticos, tal vez encontremos algunas coincidencias que puedan ayudarnos a comprender ese hilo conductor inapreciable entre esas dos maneras de abordar el fenómeno de la interpretación.

\section{La crítica al objetivismo científico como punto de partida de una hermenéutica de la finitud en Nietzsche y de Gadamer}

El punto de partida de la hermenéutica de Gadamer, como todos saben, se centró en reivindicar modos de experiencia vitales, que forman parte de la «experiencia humana del mundo", y que trascienden la "pretensión de universalidad de la metodología científica " ${ }^{3}$. Habermas, a pesar de su posición crítica frente a la hermenéutica filosófica de Gadamer, no dejó de señalar que uno de los principales logros de su hermenéutica había sido la crítica al ideal de objetividad de la ciencia, tanto en relación a la ciencia natural, como, sobre todo en relación al historicismo. El ajuste de cuentas con el historicismo, fundamentalmente por sus pretensiones de elevar a categoría de ciencia a las llamadas ciencias del espí-

I. Grondin, Hans-Georg Gadamer. Una biografia, Herder, Barcelona, 2000, p. 29.

2 H.-G. GADAMER, "Hermenéutica como filosofía práctica», en La razón en la época de la ciencia, Alfa, Barcelona, 1981 , p. 69.

${ }^{3}$ H.-G. Gadamer, Verdad y método, $I$, tr. cast. de A. Agud y R. de Agapito, Sígueme, Salamanca, 1977, p. 23 (a partir de ahora, citaremos esta obra como $V M$ ). 
ritu, como es el caso de Dilthey ${ }^{4}$, y su aspiración a grados de certeza y universalidad normalmente atribuidos a la ciencias de la naturaleza, era algo que Gadamer tenía que clarificar en orden a reivindicar un modelo epistemológico que trascendiera los planteamientos de la teoría del conocimiento tradicional de cuño cartesiano. En el fondo, se trataba de desterrar del discurso hermenéutico los elementos dogmáticos que distorsionaban la relación existencial inmediata, la ignorancia de la propia situación histórica o la autodisolución del propio sujeto en aras de lo "dado». Las razones parecían sencillas. La eliminación de las injerencias subjetivas, y la supresión de la distancia entre sujeto y objeto como condiciones de objetividad de toda comprensión, nos llevaba inexorablemente a un dogmatismo con consecuencias imprevisibles sobre la condición humana ${ }^{5}$.

En este contexto, se puede afirmar que uno de los logros inmediatos de la hermenéutica de Gadamer ha sido precisamente la superación de esos planteamientos, mediante un modelo epistémico dialógico-dialéctico, que trata de demostrar la «co-pertenencia» de hombre y tradición como constitutivo esencial de la experiencia hermenéutica. De tal manera que esa pertenencia al pasado ya no será más una limitación de la comprensión objetiva, sino una condición de posibilidad de la misma. Así pues, Gadamer siguiendo a Heidegger y yendo más allá de él, planteaba la cuestión de cómo la hermenéutica, una vez liberada de «las inhibiciones ontológicas del concepto científico de la verdad, puede hacer justicia a la historicidad de la comprensión" " elevando la historicidad del comprender a principio hermenéutico.

Como primera apreciación, podemos decir que hay una coincidencia notable entre el punto de partida de la hermenéutica de Gadamer con el planteamiento inicial de la filosofía de Nietzsche. Si es así, ¿̨se pueden reforzar entonces con Nietzsche los principios hermenéuticos de la filosofía gadameriana? Gadamer, por su parte, piensa que a través de la crítica que hace Nietzsche de las aporías del historicismo, se puede uno ya dar cuenta de las dificultades de la conciencia histórica y de su pretensión de objetividad histórica, y del alcance histórico

${ }^{4}$ Cf. mi trabajo "La hermenéutica metódica. Comprensión y objetividad en las hermenéuticas de F. Schleiermacher, W. Dilthey y E. Betti", en Estudios Filosoficos, 34 (1985), pp. 15-53.

${ }^{5}$ Cf. mi libro Tradición, lenguaje y praxis en la hermenéutica de H. $G$. Gadamer, Servicio de Publicaciones de la Universidad de Málaga, Málaga, 1987, pp. 28-38.

${ }^{6} V M$, p. 331. 
y filosófico de la crítica de Nietzsche al ideal de objetividad. En este sentido, su crítica a la ciencia filológica, como ciencia del espíritu, que busca la objetividad en los textos, es un excelente modelo y referencia para la autocomprensión de la hermenéutica.

Desde sus escritos de juventud, especialmente desde "Homero y la filología clásica", podemos apreciar ese talante anticientificista de Nietzsche, su interés por poner límites a la ciencia, su rechazo a la idea de causalidad y necesidad, y, sobre todo, sus primeras reflexiones sobre la función del arte en la manera de considerar el pasado histórico, es decir, «ver la ciencia desde la perspectiva del arte y de la vida". Todo ello abre una nueva perspectiva de gran calado que encontrará a finales del siglo XX, en las corrientes hermenéuticas, su mejor definición. En los primeros textos de su obra se puede ver ya cómo Nietzsche distingue una historia vista desde la perspectiva científico natural y una historia artística, al servicio de la vida. Por eso estaba convencido, ya desde el principio, de que frente al historiador teórico tiene que ser el poeta ${ }^{7}$ el que escriba la historia, pues de lo contrario «seria una pena - dice Nietzsche- que no fuera el poeta».

En la Segunda Consideración Intempestiva indaga la «utilidad y el perjuicio de la historia para la vida», y esboza, dice Gadamer, "una imagen tremenda de la enfermedad histórica que atacó a su época» ${ }^{8}$. Nietzsche muestra cómo todos los instintos vitales promotores de la vida se corrompen profundamente con esa enfermedad, cómo todas las pautas y valores vinculantes se diluyen cuando se miden con unas normas ajenas y arbitrarias y con tablas axiológicas en constante cambio. Pero la crítica de Nietzsche tiene su lado positivo, como indica Gadamer, ya que proclama "la normatividad de la vida, que calibra la dosis de historia que una cultura puede tolerar sin prejuicio»". Es indudable que en relación

7 Ibíd., p. 284.

${ }^{8}$ Cf. H.-G. GaDAmER, "El problema de la historia en la reciente filosofía alemana" (1943), en Verdad y Método II, Sígueme, Salamanca, p. 38 (a partir de ahora, citaremos esta obra como $V M I I)$.

9 Ibíd. Gadamer nos dice un poco antes (p. 33): «Todavía resuena en nuestros oídos la critica que F. Nietzsche hiciera a la historia en la célebre segunda Consideración intempestiva. ¿Es realmente el sentido histórico esa espléndida ampliación de nuestro mundo que el siglo XIX vio en él? ¿No es más bien señal de que el hombre moderno no posee ya un mundo propio desde que ha aprendido a mirar al mundo con cien ojos a la vez? ¿No se disuelve el sentido de la verdad cuando se hacen conscientes las perspectivas cambiantes en las que esta aparece?". 
con Gadamer, Nietzsche radicaliza aún más esa crítica al historicismo al considerarlo en realidad como una verdadera "enfermedad" o "hipertrofia" que altera la relación de la historia con la vida, y cuestiona el hecho de que la vida pueda ser comprendida, ante todo, como un acontecer histórico para el hombre. Pero Nietzsche, lo mismo que Gadamer, vio que la causa principal de esa enfermedad no era otra sino "la exigencia de que la historia debe ser ciencia" $(1,271)^{10}$, o en otros términos, la oposición que se da "entre vida y sabiduría" $(1,257)$. Y contra las pretensiones de validez y universalismo de la ciencia histórica, Nietzsche opta por una mayor beligerancia que Gadamer y lleva a la historia, como hizo Kant con la ciencia, ante el tribunal de la vida. Tras los fenómenos históricos busca lo que acontece en el fondo de la verdadera realidad, abriendo un escenario nuevo frente al idealismo, a la razón absoluta, al historicismo, al progreso y a la historia, que habían creado una falsa atmósfera de optimismo.

Esto no significa que estemos ante la negación de la historia, ni ante un veredicto contra cualquier manera consciente de guiarnos en la vida, sino ante un veredicto que se vuelve contra los "desordenes" del saber histórico y contra la sobrevaloración de los resultados de la conciencia, en definitiva, contra «los excesos de historia». Nietzsche quiere ante todo invertir aquel principio cartesiano que había abierto las puertas a la modernidad, el "cogito, ergo sum", por el "vivo, ergo cogito" $(1,329)$. La vida, la experiencia vital, es lo que produce el conocer, y este reconocimiento originario es lo que ha de poner limites al propio saber que, a su vez, debe "clavar el aguijón contra sí mismo" $(1,306)$, pues «jestamos condenados a oír eternamente la hipérbole de todas las hipérboles, la palabra, mundo, mundo, mundo, cuando cada uno, de modo sincero, sólo debería hablar del hombre, hombre, hombre!n $(1,312)$. Por eso es por lo que Nietzsche plantea ya en un primer momento una especie de transvaloración en la relación de la vida humana con la historia, en la relación del hombre con el pasado o la tradición.

Nietzsche, que siempre sostuvo una estrecha relación entre conocimiento y praxis vital, entre vivir y conocer $(1,257)$, no podía soportar que la ciencia histórica dejase el pasado en un estado de esclerosis total, en lugar de apropiarse de él en orden a la acción. La ciencia en general, dice, «no puede jamás impartir

${ }^{10}$ Con esta numeración ( $\mathrm{y}$ todas cuantas subsiguen entre paréntesis a lo largo de este escrito) hacemos referencia al volumen y a la página de F. NIETZSCHE, Sämtliche Werke. Kritische Studienausgabe (KSA), ed. de M. Montinari y G. Colli, W. de Gruyter, Múnich, 1980, vol. 1, p. 285. 
órdenes al hombre. Inclinación, amor, placer, dolor, exaltación, creación [...] nada de esto conoce la ciencia. Lo que el hombre vive y experimenta, tiene él que interpretarlo para sí desde alguna parte; y de acuerdo con ello, valorarlo" (7, $429)^{11}$. Y es que la ciencia, siguiendo un modelo holístico, despliega "las redes de un pensamiento global sobre la totalidad del mundo" $(1,97)$, celebrando sus Saturnales, pues sus resultados, por mínimos que sean, son considerados superiores a todas las ideas metafísicas $(1,285)$. Por eso, para Nietzsche, el historicismo es una consecuencia de la cultura socrático-alejandrina y, a su vez, un síntoma de la parálisis de la fuerza vital mediante el saber y el conocimiento, una manera de compensar la debilidad y la falta de vida, producidas por esas "piedras del saber" que son el cientificismo de la historia, y que tan indigestas son para el hombre individual y para su desarrollo y formación.

\section{La hermenéutica de Gadamer y los implícitos hermenéuticos de la «Segunda Consideración Intempestiva»}

Para poder apreciar los implícitos hermenéuticos en la filosofía de Nietzsche $\mathrm{y}$, de esa manera, poder valorarlos frente a la hermenéutica de Gadamer, es necesario proceder hermenéuticamente y dejar que hable de nuevo ese escrito de Nietzsche ya mencionado, la Segunda Consideracion Intempestiva, "Sobre la utilidad y perjuicios de la historia para la vidam. Heidegger, en Ser y Tiempo, salía en defensa de Nietzsche afirmando que la historia puede servir a la vida, pues «la vida es histórica en las raíces mismas de su ser", y decía que Nietzsche lo había comprendido y dicho de un modo penetrante e inequívoco - en la segunda de sus Consideraciones Intempestivas $(1874)^{12}$, en la que «él comprendía más de lo que daba a conocer)además, es él mismo el que hace la historia, y, en este sentido, la historia no es de ninguna manera el espacio temporal que existe desde un principio y para todo futuro, que se llenaría a través de la acción humana. De ahí que al hacer la historia se cree con ello no sólo su propia cultura, sino su propio tiempo y su propia obra. El tiempo y la historia se le abren mediante su propio hacer.

Del escrito de Nietzsche podemos destacar brevemente algunas facetas que pueden orientarnos en nuestra pretensión de valorar aspectos hermenéuticos de

$"$ F. NIETZSCHE, Werke, ed. de Kart Schlechta, Hauser, Múnich, 1977, III, 243.

12 M. HeIDEgGer, Ser y tiempo, tr. de J. E. Rivera, Trotta, Madrid, 2003, p. 411 (SZ, 396). 
su pensamiento y sugerirnos ideas complementarias en relación a la gran obra de Hans-Georg Gadamer. Por ejemplo:

1. Su crítica al objetivismo científico, como ya hemos señalado, que después reivindicaría Gadamer, y que Habermas la considera como una de las mejores contribuciones de la hermenéutica al pensamiento actual.

2. La reivindicación de los griegos presocráticos como modelo de "lo clásico".

3. La manera en que comprende la apropiación del pasado.

4. El significado de la "historia efectual" en su pensamiento.

5. La productividad hermenéutica del concepto de "fuerza plástica».

6. La introducción del elemento crítico y reflexivo frente a la tradición.

7. Reivindicación del arte como modelo de experiencia hermenéutica fundamental.

8. La determinación de la idea de horizonte como elemento más adecuado que el de "prejuicio», etc.

Como se pude apreciar a primera vista, estos aspectos temáticos, que de una $u$ otra manera aparecen en el primer Nietzsche como connotaciones de su crítica al historicismo, pueden sugerirnos esa aproximación Gadamer-Nietzsche, sin caer en el reduccionismo violento que busca contra natura acercar posiciones irreductibles.

Que Gadamer está de acuerdo con Nietzsche, sobre todo en algunos de sus planteamientos de su Segunda consideración Intempestiva, parece evidente. Él mismo hace hincapié en cómo Nietzsche plantea adecuadamente la contradicción entre "la voluntad de formación inmediata que hay siempre en el presente» ${ }^{13} y$ el postulado de Ranke sobre la «autodisolución de la individualidad». Es lo que llama Nietzsche el "talante vital alejandrino", un talante debilitado que es modélico para la conciencia moderna incapaz de hacer una valoración propia de los fenómenos. «La ceguera axiológica - parafrasea Gadamer- propia del objetivismo histórico desemboca así en el conflicto entre el mundo histórico enajenado y las fuerzas vitales del presente». La cuestión hermenéutica fundamental se cifra, entonces, en ver cómo entiende Nietzsche la relación entre pasado y presente, a fin de poder establecer algún nexo con la hermenéutica gadameriana.

13 H.-G. GADAMER, "La universalidad del problema hermenéutico", en $V M, I I$, p. 215. Cf. H. Schröter, Historische Theorie und geschichtliches Handeln. Zur Wissenschaftkritik Nietzsches, Männder, Mittenwald, 1982, p. 236 s. 
Para Nietzsche el pasado, el mundo antiguo, hay que estudiarlo como si fuera también un tú, un ser humano ejemplar, al que se puede imitar, conservar, y criticar. Esta posición respecto al pasado engloba la tesis fundamental de Nietzsche de que la "historia tiene que estar al servicio de la vida" y lo puede hacer de esas tres formas: dando lugar a la historia monumental, anticuaria y critica. Estas tres maneras de relacionarse con el pasado, son algo así como dimensiones historiográficas de la conciencia histórica ${ }^{14}$, y son mencionadas como una especie de estrategia para garantizar al hombre un horizonte histórico en el que pueda vivir, una relación con lo sido, con el pasado. Heidegger decía que esta "triplicidad del saber histórico está bosquejada en la historicidad del Dasein. La historicidad del Dasein hace comprender también hasta qué punto el modo propio del saber histórico debe ser la unidad concreta y fáctica de estas tres posibilidades" ${ }^{15}$. Por lo tanto, Heidegger cree que es importante tener en cuenta que esos tres modos de saber históricos hay que pensarlos en su "unidad fáctica», aunque el propio Nietzsche no dé cuenta de la necesidad de esa tríada ni del fundamento de su unidad. El mismo Gadamer insiste también en que esas tres maneras de entender la autoconciencia histórica hay que comprenderlas dentro de un "equilibrio adecuado" ${ }^{16}$. Por eso, cuando tratamos de elucidar la manera en que Nietzsche mira el pasado, podemos aventurar la hipótesis de que está formulando los distintos momentos de un diálogo permanente con la tradición en el que se considera el modo de ser del objeto, el pasado (Historia monumental), el modo de ser del sujeto, el presente (Historia anticuaria), y el momento de la reflexión, la crítica (Historia crítica). Veamos algunos aspectos de esta especie de "dialéctica hermenéutica»:

En primer lugar encontramos un modelo ejemplar de la "historia que actúa», "historia efectual", en los filósofos preplatónicos y en el modelo de «lo clásico». Nietzsche, como Heidegger después, piensa que los presocráticos, los "pensadores icarios ${ }^{17}$, no son los predecesores de Platón sino sus antípodas; en particular, porque identifican vida y filosofia y de esa manera constituyen una «fuerza» que

14 Cf. E. Mazzarela, Nietzsche e la Storia. Storicita e ontologia della vita, Guida, Nápoles, 2000 , p. 44.

15 M. HeIDEGGER, op. cit., p. 411;SZ, 396.

16 H.-G. GADAMER, "El problema de la historia en la reciente filosofía alemana" (1943), op. cit., p. 38.

$K S A, 8,118$. 
actúa en la historia de una manera ejemplar. Este pasado tiene un modo de ser "intempestivo", lo cual significa en cierta medida la posibilidad de poder "oír" como más próxima y cercana la voz de la tradición. Pero además, el modo de pensar de los primeros filósofos griegos constituye un modelo «ejemplar» que hay que "conservar" 18 , pues Nietzsche estaba convencido de que las ideas griegas habían de ser comprendidas históricamente, a la luz de sus efectos y desarrollos posteriores. Esto explica que a esos "maestros de vida" se les considere «individuos ejemplares", que pueden servir de criterio determinante para nuestro presente, porque poseen una "fuerza» que determina el modo de ser de la historia de la humanidad occidental»" ${ }^{19}$.

Pero también es ejemplar la Antigüedad griega en general, porque fue capaz de transformar aquella fuerza dionisiaca devastadora y dominarla mediante el espíritu apolíneo, que sublimó aquella fuerza bajo el signo del agón. Nietzsche traslada este poder tensional, cuasidialéctico, que se daba entre los griegos en el "certamen" (Wettkampf), o luchas competitivas, a la relación entre presente y pasado. De tal manera que si en la Antigüedad griega el agón, junto con la liberación de nuevas formas de vida, contribuyó a una renovación fundamental, también la Modernidad en lucha competitiva con la Antigüedad debe incrementar las fuerzas para su propia renovación ${ }^{20}$. Con el pensamiento de la lucha competitiva parece estar resuelto lo que se le presenta al joven filólogo Nietzsche como la antinomia de su especialidad: que la Antigüedad es una materia limitada y no inagotable de la filología, y su tarea de comprender mejor la propia época a través de la Antigüedad es, por el contrario, eterna ${ }^{21}$.

Gadamer, lo mismo que Nietzsche, cree que la autocrítica de la filología en relación a sus objetos recuperó el verdadero sentido de "lo clásico» ${ }^{22}$. Lo clásico

${ }^{18}$ F. NIETZSCHE, Die Philosophie im tragischen Zeitalter der Griechen, KSA 1, pp. 801-872, aquí: p. 801 .

${ }^{19}$ H.-G. GADAMER, Die neue Platoforschung (1933), en Gesammelte Werke (en lo sucesivo lo citaremos como GW), vol. 5, pp. 212-229, aquí, p. 228. Cf. también C. H. ZUCKERT, Postmodern Platos. Nietzsche, Heidegger, Gadamer, Strauss, Derrida, University Chicago Press, Chicago, 1996, p. 30.

${ }^{20}$ Cf. M. WISCHKE, "Ist es notwendig, die Vergangenheit zu verstehen? Friedrich Nietzsche und Hans-Georg Gadamer über das "Rätsel der Wertsetzung"", en Perspektiven der Philosophie. Neues Jahrbuch, 28 (2002).

${ }^{21} K S A, 3,3[62], 31$.

$22 V M$, p. 354. 
«es una realidad histórica a la que sigue perteneciendo y estando sometida la conciencia histórica misma" ${ }^{23}$. Es, sin duda, la conciencia de lo permanente, de lo intempestivo que no se somete a una circunstancia temporal. Y esto es así porque, según Gadamer, es una «especie de presente intemporal» que significa «simultaneidad" con cualquier presente. Así pues, lo clásico como pasado es inasequible, pero es algo presente. Recordando a Hegel, "lo clásico es lo que se conserva porque se significa e interpreta a sí mismo" ${ }^{24}$. Nietzsche no tendría ningún inconveniente en ratificar esta relación con el pasado, pues precisamente esa elocuencia, algo que habla por sí mismo, no es un mero objeto que necesite interpretación, sino que continuamente dice algo a cualquier presente. Esa forma intempestiva, por tanto, no requiere que se supere "la distancia histórica» por medio de metodologías científicas o reconstructivas del pasado, sino que, como dice el propio Gadamer de un modo hermenéutico, "está continuamente realizando esta superación con su propia mediación» ${ }^{25}$. Así pues, no basta la reconstrucción, sino la conciencia de la pertenencia a ese mundo y con ello, recíprocamente, la pertenencia de la obra a nuestro mundo, por lo tanto la co-pertenencia de pasado y presente.

Pero para Gadamer es importante hacer notar que ese sentido de lo clásico, que para Nietzsche tenía su modo de ser en el poder de determinación del presente, tal y como se manifiesta en la historia monumental, se reducía en lo esencial a esa "fuerza del decir" (Sagkraft) de una obra del pasado que es, en primer lugar, duradera e inmediata, y en segundo lugar es fundamentalmente «ilimitada". De este modo, Gadamer corroboraba ese principio hermenéutico según el cual un escrito, y más aún un escrito clásico, nunca debe poder ser comprendido del todo, pues siembre cabe la posibilidad de ser comprendido de otra manera, o como diría Nietzsche, desde otra perspectiva o como una nueva interpretación. Con lo cual la validez permanente de lo clásico determina la mediación histórica del pasado con el presente, pues tanto el pasado como el presente se hallan en continua mediación. En Gadamer esto se explica mediante la "conciencia de la historia efectual», en Nietzsche a través de la mediación entre el «sentido normativo" del pasado, y el presente, pues "la necesidad de vida exige lo clásico» ${ }^{26}$,

\footnotetext{
23 Ibíd., 357.

${ }^{24}$ Ibíd., 359.

25 Ibíd.

${ }^{26} K S A$, VII, 29 [29].
} 
y en esa medida «trata el pasado con arte y con una fuerza artística transfiguradora". Por eso en el mismo texto se dice que la vida exige la «equiparación (Gleichsetzen) del presente con el pasado". Pero para comprender mejor la posición de Nietzsche en relación con el pasado y la tradición conviene puntualizar el sentido de la co-pertenencia desde ese concepto tan productivo y fundamental en la hermenéutica de Gadamer como es el de la «conciencia de la historia efectual». Como hemos visto, parece que en Nietzsche se mantiene el carácter de «acción» (Wirkung) de la historia (Geschichte) desde el punto de vista de la historia monumental.

\section{La "apropiación" del pasado por el presente. La funcionalidad del concepto de «fuerza plástica"}

Que la teoría de la historia de Nietzsche, o sus reflexiones sobre la relación entre el pasado y el presente, parecen fundamentarse hermenéuticamente ${ }^{27}$, es algo en lo que algunos estudiosos están de acuerdo. La hermenéutica acentúa que en el acto de la apropiación del pasado, o de la tradición, está la condición de la autorrelación actualizante, sin la que sería imposible la comprensión. En cierto sentido se pude decir que el concepto de Nietzsche de fuerza plástica ${ }^{28}$ puede ser interpretado como concepto hermenéutico de la apropiación y, como tal, habría que decir que se adelanta a algunas de las ideas que posteriormente utilizará Gadamer en su hermenéutica.

Esa "fuerza" no se entiende como un simple «saber interior», sino que es una fuerza que da forma a la historia, como la del artista cuando crea su obra. Es necesaria, porque la historia ya no se forma a sí misma, a diferencia de Hegel. Esa fuerza tiene ya en sus primeros escritos una finalidad transformadora, que Nietzsche puntualiza en los siguientes términos: se trata de "transformar" y "asimilar (einverleiben) lo pasado y lo extraño" en familiar, mediante el ejercicio de la apropiación, "pensando, reflexionando, comparando, separando y sintetizando» $(1,253)$. Este texto tiene gran importancia por varias razones. En primer

${ }^{27}$ Esta es la opinión de K. MEYER en su obra Ästhetik der Historie, Königshausen \& Neumann, Wurzburgo, 1998, p. 126.

28 Posiblemente Nietzsche lo haya tomado de Burckhardt. Lo adopta en un sentido psicológico y lo considera como una propiedad de la juventud (J. BURCKHARDT, Die Kultur der Renaissance in Italien. Ein Versuch, vol. 2, ed. de L. Geiger, Leipzig, 1908, p. 219). 
lugar porque Nietzsche en este caso tiene presente el modelo de la vida, en el mismo sentido que lo utilizó, por ejemplo Hegel, y al que Gadamer se remite ${ }^{29}$ en Verdad y Método. La conservación de la vida implica incorporar en sí lo que existe fuera de ella, pues todo lo vivo se nutre de lo que es extraño. Así pues, el hecho fundamental de estar vivo es la asimilación en la que lo extraño se hace propio, o como diría Gadamer, «familiar». Por lo tanto, la única manera de poder concebir la vitalidad es haciéndose cargo de ella (autorreflexión, autocomprensión, o autoconciencia). En segundo lugar, porque Nietzsche introduce en la apropiación un momento de "reflexión", aunque Gadamer no lo ve del todo claro. Sin embargo, ese tomar conciencia del pasado lo ilustra Nietzsche por medio de una imagen: «el árbol siente sus raíces más de lo que pude verlas, pero ese sentimiento mide toda su grandeza según la grandeza y fuerza de sus ramas visibles» $(1,267)$. En seguida nos viene a la memoria aquella proposición hermenéutica gadameriana según la cual "la conciencia de la historia efectual es finita, en un sentido tan radical que nuestro ser, tal como se ha configurado en el conjunto de nuestros destinos, desborda esencialmente su propio saber de sí mismo" ${ }^{30}$.

Así pues, el propio Nietzsche parece acentuar también el acto de tomar conciencia de aquello que nos determina, aunque no deja de ser cierto que en este caso Nietzsche acentúa el primado del sujeto con el fin de desechar el criterio de la objetividad del historicismo. Esa fuerza del pasado, tal y como la interpreta la historia monumental, es precisamente la que hace que el individuo se enriquezca, porque es la fuerza que hace "crecer a un individuo, a un pueblo, a una cultura", la que "hace curar las heridas, reemplazar lo perdido, generar las formas destruidas» $(1,251)$. Si pudiésemos expresar hermenéuticamente esa idea, podríamos decir con una cierta prudencia que Nietzsche nos está describiendo el modo de ser de la "experiencia hermenéutica». Recordemos cómo Gadamer ponía el énfasis en que el resultado de la experiencia hermenéutica era precisamente que en el individuo se daba un incremento del $\operatorname{saber}^{31}$ y una mayor autocomprensión o, en otros términos, surgiría algo «nuevo» de la confrontación entre el pasado y el presente.

\footnotetext{
${ }^{29} V M$, p. 317.

30 VM, pp.16-17.

$31 V M$, p. 431.
} 
$\mathrm{Y}$ es que para Nietzsche comprender el pasado es un acto creativo ${ }^{32}$, pues lo importante es "hacer historia", y no registrar los hechos tal y como ocurrieron realmente. "Tened el valor de hacer historia", decía Nietzsche $(7,611)$ a modo de imperativo categórico. Pero hacer historia es una tarea propia de artistas: el historiador se asemeja al artista que construye una historia y se sirve del material positivo de la ciencia histórica. Los objetos de la historia hay que tratarlos como si «de los bloques de los hechos históricos nosotros tuviéramos que sacar sólo estatuas» ${ }^{33}$. De esta manera, al mismo tiempo que se comprende el pasado, el hombre se autocomprende, se va creando a sí mismo como una obra de arte que nunca llega a ser perfecta o absoluta, como le hubiera gustado a Hegel, sino que se entiende como un proceso infinito que solo será interrumpido por la muerte, pues al existencia es "un imperfectum que nunca llegar a realizarse de modo completo» $(1,249)$. En este sentido, el propio Gadamer nos remite al momento de la aplicación en la hermenéutica, en la que se identifica comprensión y autocomprensión, pues en realidad, cuando el filólogo trata de comprender un texto dado, lo que hace es «comprenderse a sí mismo en el texto" ${ }^{34}$.

Como se pude apreciar, Nietzsche introduce sin reservas el elemento estético como algo esencial en la confrontación entre el presente y el pasado ${ }^{35}$. En este sentido, y volviendo a la idea de "fuerza plástica", representa una fuerza artística análoga a la fuerza plástica de Apolo, que se basa en el «sometimiento», en la "contención", en poner límites a la fuerza dionisiaca que se desborda. Así pues, la fuerza plástica ejerce una doble función. Por una parte, desde el punto de vista de la historia anticuaria, moldea la tradición o el pasado a tenor de los intereses artísticos del presente, en virtud de esa «capacidad de empatía, de adivinación, de olfatear las huellas casi extinguidas, del instinto de leer correctamente el pasado por más que se haya escrito encima, una rápida capacidad de comprender los palimpsestos, e incluso los polipsestos..." $(1,264)$. Esa fuerza plástica de la historiografía se prefigura también en la imagen del sueño apolíneo. De la misma manera que en la formación de los sueños, el historiador, «recupe-

${ }^{32}$ Cf. C. LIPPERHEIDE, Nietzsches Geschichtstrategien. Die rhetorische Neuorganisation der Geschichte, Königshausen \& Neumann, Wurzburgo, 1999, p. 15.

${ }^{33}$ F. NiETZSCHE, Gesammelte Werke (Musarionausgabe), Múnich, 1920-29, vol. I, p. 283.

${ }^{34} V M$, p. 414.

${ }^{35}$ Sobre la estética de Nietzsche en general, y sobre el modo de ser de la creación artística me remito a mi obra: Arte y poder. Aproximación a la estética de Nietzsche, Trotta, Madrid, 2004. 
ra lo perdido y regenera las formas destruidas" $(1,251)$, "transforma" y "asimiLa". Por eso, para Nietzsche la historia es en grado sumo productiva, en cuanto que la fuerza plástica transforma los hechos históricos y en esa medida el hombre se transforma a sí mismo, pues en realidad, quien cultiva la historia busca en la apropiación del pasado un símbolo de sí mismo, con lo cual se construyen dos relatos, el del pasado y el del yo. Pero, por otra parte, tampoco hay que olvidar que en la historia monumental, que está al servicio de la vida, el yo debe medirse en la grandeza del pasado, aunque también es cierto que sólo se constituye la grandeza del pasado según la medida del yo. Esta dependencia recíproca la compara Nietzsche con la interpretación de un oráculo. El oráculo no tiene ningún sentido objetivo, ofrece al que busca el punto de partida para encontrar el sentido, y aquel que mejor conozca el pasado será el que mejor interprete la voluntad de los dioses.

El hombre, por tanto, necesita la historia para interiorizarse con el propio origen: la necesita para superar lo que ya ha sido, apoyándose en los impulsos de su presente para proyectarse hacia el futuro. Nada del pasado está definitivamente muerto, como un hecho frío y aislado, como pensaban los historicistas: continúa reviviendo en el presente. El pasado siempre se descubre, aunque parezca ya conocido, y se convierte en un nuevo impulso. Ese saber tiene que ser vivo, activo, testimonia la historia verdadera, y jamás se sabe de modo definitivo lo que ha sido. Todo lo que ha sido depende de lo actual, del presente a partir de cuyos impulsos la historia vuelve a ser lo que le corresponde: medida, modelo e imagen. «Sólo desde la fuerza poderosa del presente podéis vosotros interpretar el pasado" $(1,293-4)$. Por eso, los verdaderos historiadores serán aquellos que posean la «fuerza de volver a formular lo ya conocido como algo nunca visto antes» (1, 259). Esos son para Nietzsche los arquitectos del futuro, los que tienen una experiencia superior, los artistas. Los espíritus poderosamente artísticos, «los que son capaces de aprender para la vida y traducir lo que han aprendido en una práctica más elevada" $(1,263)$, los "maestros" que adivinarán lo que es grande en el pasado, pues «jlo semejante se descubre por medio de lo semejante!» $(1,294)$.

De todo lo que hemos dicho, podemos ya deducir que tanto Nietzsche como Gadamer no comparten la actitud de neutralidad del sujeto, o las teorías de la "autodisolución» del sujeto como garantía de la objetividad histórica. Esto para Nietzsche significaría un debilitamiento progresivo de la propia subjetividad, quedando el individuo reducido a pura pasividad, al tratar de anular su posición y 
situación hermenéuticas con tal de salvar la objetividad de los hechos. Todo ello genera, según Nietzsche, un sujeto débil y enfermizo, con la mente embotada (1, 299), que "ha perdido y destruido su instinto" $(1,280)$ incapaz de poder aplicar el pasado al presente, o apropiarse de él, pues esa forma suprema e idealista de objetividad nos remite a un estado en el que el historiador "contempla un acontecimiento de una forma tan pura que no produce sobre su sujeto ningún efecto" $(1,289)$. En este sentido, Nietzsche nos está diciendo que la tradición actúa realmente sobre el sujeto, y que precisamente por eso "el hombre llega a ser hombre cuando transforma la historia pasada en historia presente" $(1,253)$. Pero es consciente, al mismo tiempo, que el pasado no puede llegar a cegar el poder del acto creador en el presente. Por eso, reivindica de una manera firme la necesidad de un sujeto fuerte para medirse con el pasado, pues usólo las personalidades fuertes pueden soportar la historia; los débiles son barridos completamente por ella» (1, 283). Al fin y al cabo, el propio Gadamer nos enseña que en la hermenéutica es necesario, si queremos comprender el pasado o la tradición, «mediarlo con el presente de su propia vida" ${ }^{36}$, para poderlo mantener abierto hacia el futuro.

De este modo, tanto Nietzsche como Gadamer nos enseñan el camino para salir del círculo del ideal de la objetividad de la hermenéutica generado por el ideal de la ciencia y por el historicismo, evitando el «autoolvido" del sujeto y del propio presente. Pero lo cierto es que esa actitud del sujeto no tiene nada que ver con la absolutización del presente a la manera de Hegel, pues ese sujeto, que por otra parte ya no es tal, se relaciona con la tradición o la historia dejando también que la tradición sea, es decir, dejándola que insinúe - no que muestre de un modo absoluto- el "profundo sentido, poder y belleza" que hay detrás de la apariencia de las cosas. Pero para ello, Nietzsche reivindica, como hemos visto, una "gran potencia artística», "un abismarse amoroso en los datos empíricos", "una continua poetización de los tipos dados" $(1,292)$.

Pero para evitar malentendidos Nietzsche completa su comprensión del pasado introduciendo una tercera forma de entender la historia, la historia crítica, un preanuncio de lo que será después su método genealógico. La introducción de ese elemento crítico es interesante, pues en este sentido Nietzsche también se adelanta a lo que posteriormente también sería relevante en el campo de la her- 
menéutica de la Teoría Crítica (Habermas y Apel) y en la polémica que sostuvo con Gadamer al respecto. Nietzsche de una manera gráfica nos dice que hay que llevar también a juicio al pasado. Pero se trata de un juicio muy peculiar, porque no se hace en nombre de la justicia sino en nombre de la vida: "es únicamente la vida quien aquí se expresa, ese poder oscuro e incitante, ese poder que con insaciable afán se desea a sí mismo" $(1,268)$. Por eso el juicio de la vida es siempre injusto, pues su resultado es "condenar el pasado", ya que todo pasado es digno de ser condenado.

Nietzsche, como heredero de la Ilustración ${ }^{37}$, considera que el hombre tiene que emanciparse críticamente de sus vínculos con el pasado, y para ello debe tener primero la fuerza de "destruir y liberarse del pasado, para poder vivir» (1, 269), y utilizarla de vez en cuando. Pero no se trata aquí de una destrucción radical, sino más bien de una "desmitologización», de una «destrucción temporal» que tiene como finalidad que resplandezca aquello que constituye la "grandeza" del pasado. En un texto de la Gaya ciencia vuelve a corroborar esa idea en estos términos: "Todo gran hombre tiene una fuerza retroactiva. Toda la historia se pone por su causa de nuevo en la balanza y mil secretos del pasado salen de sus escondrijos arrastrándose hacia su sol. No hay modo de decir lo que puede todavía llegar a ser una parte de historia. ¡Puede que el pasado esté quizás todavía esencialmente sin descubrir! ¡Se necesitan tantas fuerzas retroactivas todavía! » ${ }^{38}$.

En este sentido, la actitud crítica de Nietzsche está mediatizada por la reflexión en su "conciencia de la historia efectual» - utilizando la terminología de Gadamer-, pues no basta simplemente con afirmar que no podemos «librarnos completamente de esta cadena" $(1,270)$, sino que hay que tomar conciencia de que somos el resultado de las generaciones anteriores, pero también somos el resultado de sus errores y de sus pasiones. $Y$ de una manera categórica afirma que "a pesar de creer que nos hemos emancipado de ellos, de hecho no podemos dejar a un lado que nosotros procedemos de ellos". Pero alcanzar una perspectiva crítica no quiere decir que uno se esté saliendo fuera de la historia para obtener una objetividad universal, tal y como Gadamer respondía a las objeciones de Habermas. Esto no es posible por la complejidad de la historia: nosotros sólo podemos estructurar nuestra comprensión de la historia.

37 Cf. F. NietzsCHE, Aurora, A $\$ 197$, donde habla de la función histórica de la llustración.

38 F. NietZsCHE, Gaya Ciencia, $\$ 34$ (KSA, 3, 404). 
Un ensayo de aproximación de dos hermenéuticas tan ricas como la de Nietzsche y la de Gadamer es un camino fecundo que puede ayudarnos a comprender mejor la hermenéutica de este último dentro de una tradición que pasa por Nietzsche, $\mathrm{y}$ al mismo tiempo a descubrir los implícitos hermenéuticos que oculta la filosofía de Nietzsche. A nadie se le escapa ya que los planteamientos sobre la interpretación de este sentaron las bases a desarrollos hermenéuticos posteriores, pero tal vez no se ha hecho todavía justicia a Nietzsche respecto a su hermenéutica. Las razones parecen obvias. Un autor tan radical y asistemático, que insinúa más que dice, no da facilidades para elaborar un cuerpo hermenéutico estructurado como el de Gadamer; pero eso no tiene que ser un obstáculo para seguir oyendo sus infinitas sugerencias. 